\title{
Age Differences in Risk: Perceptions, Intentions and Domains
}

\author{
EMILY M. BONEM*, PHOEBE C. ELLSWORTH and RICHARD GONZALEZ \\ Department of Psychology, University of Michigan, Ann Arbor, MI USA
}

\begin{abstract}
Although it is commonly assumed that older people are more cautious and risk averse than their younger counterparts, the research on age differences in risk taking is mixed. While some research has found that older adults are less risk seeking, other research has found the opposite or no differences. One explanation is that age differences vary across risk domains. In two studies, we surveyed three adult age groups ranging in age from 18 to 83 on their risk perceptions and intentions of risky behaviors across several domains. Our studies showed that compared with young adults, older adults tend to see more risk in behaviors in health and ethical domains but less risk in behaviors from the social domain. A similar pattern occurred for participants' intentions of engaging in the risky behaviors. Older adults rated risky behaviors from health and ethical domains as less enjoyable and less likely to produce gains than young adults, whereas they rated risky behaviors from the social domain as more enjoyable, less unpleasant, and less likely to produce losses than young adults. These results suggest that age differences in risk preferences may vary across domains and may result from differing motivations. Copyright (C) 2015 John Wiley \& Sons, Ltd.
\end{abstract}

KEY WORDS risk taking; risk preferences; older adults; domain-specific risk

\section{INTRODUCTION}

What constitutes a risky situation? Most people would agree that unprotected sex and recreational drugs are risky. However, what about taking a shower? A New York Times story by Jared Diamond (2013) suggested that everyday activities like a shower can be dangerous for older adults. Nevertheless, even if everyone agreed that showers are risky, would we then all stop showering after the age of 65 , probably not because showering also has benefits. This example illustrates that we sometimes do things even when we know they are risky and highlights the importance of a lifespan perspective when studying risk.

\section{Older adults and risk}

The general stereotype of older adults is that they are more cautious than younger people (e.g., Heckhausen, Dixon, \& Baltes, 1989). However, this stereotype does not always hold true. For instance, when controlling for factors including race, socioeconomic status, and gender, older and younger adults have equal pathological gambling rates (Welte, Barnes, Wieczorek, Tidwell, \& Parker, 2001). Unsafe sex has also increased among older adults, and approximately $25 \%$ of all people living with HIV/AIDS are 50 or older. This is not simply because people with HIV/AIDS now live longer: $15 \%$ of newly diagnosed cases are in people 50 and older (CDC, 2008). These statistics imply that older adults may be less risk averse than assumed.

Research on older adults' risky behavior has also shown mixed results. Older adults consistently report less impulsivity and sensation seeking on personality scales than young adults (e.g., Patton, Stanford, \& Barratt, 1995; Spinella, 2007). Also, early studies found that older adults rated risky outcomes as

\footnotetext{
*Correspondence to: Emily Bonem, Department of Psychology, University
} of Michigan, Ann Arbor, MI, USA. E-mail: ebonem@umich.edu more likely and tended to choose less risky options in hypothetical scenarios (e.g., Botwinick \& Thompson, 1966; Chaubey, 1974; Kogan \& Wallach, 1961). However, more recent studies suggest that older adults' decisions are not affected by risk (e.g., Chou, Lee, \& Ho, 2007; Dror, Katona, \& Mungur, 1998; Reece et al., 2010). For instance, several studies using the Iowa Gambling Task found no differences in risk aversion between the two age groups (Kovalchik, Camerer, Grether, Plott, \& Allman, 2005; MacPherson, Phillips, \& Della Sala, 2002). Some studies have even found more risk seeking in older adults (e.g., Samanez-Larkin, Kuhnen, Yoo, \& Knutson, 2010). Several explanations have been suggested for these inconsistent results. In an early review of the literature, Okun (1976) observed age differences on a choice dilemma task (where participants are forced to choose between a risky and a less risky option) when participants were allowed to skip questions but not when the participants were forced to answer all questions. Thus, while older participants may be more likely to avoid risky choices, they may not be more risk avoidant when a decision must be made.

Another proposition was that the absence of age differences in some lab studies was because of cognitive impairments or external factors (Dror et al., 1998). Because unhealthy participants are usually excluded in lab studies, age differences did not occur. In other words, older adults with poor health or cognitive deficits may contribute to the statistics that show older adults as more risk averse, but these people usually do not participate in lab studies. Thus, the specific population studied could be important in understanding how older adults deal with risky situations. Other explanations of the inconsistent results have examined the information provided in different risk tasks (Zamarian, Sinz, Bonatti, Gamboz, \& Delazer, 2008), the presence of certain versus uncertain choices (Mather et al., 2012), and the role of learning in risky decision making (Rolison, Hanoch, \& Wood, 2012).

Figner and Weber (2011) suggest that people's attitude toward risk is not a single trait but rather an interaction 
between individual differences (such as age and gender) and the situation (such as type of risk domain). For example, male adults might take more recreational risks but fewer social risks. Therefore, we should be cautious about generalizing results from a single population or risk task and should examine risky behavior across a variety of populations and risk domains.

\section{Risk domain}

Although risky attitudes are often considered a stable personality trait (e.g., Weber, 1998), they also vary across domain (e.g., Blais \& Weber, 2006; Schoemaker, 1990). A few studies have suggested that age differences may depend on risk domain (e.g., Roalf, Mitchell, Harbaugh, \& Janowsky, 2012; Wallach \& Kogan, 1961), yet most studies involving older adults and risk focus on a single domain. For example, most risky behavioral tasks involve gambles in which participants choose between more risky and less risky options, and many risk perception tasks focus on health risks. These two types of risk may not produce similar results for the same populations.

Weber, Blais, and Betz (2002) developed the DomainSpecific Risk-Taking (DOSPERT) scale, which examines individual differences in risk perception and risk preference across five domains of risk: ethical (e.g., cheating on an exam), financial (e.g., betting money on a sporting event), health/safety (e.g., riding a motorcycle without a helmet), recreational (e.g., bungee jumping), and social (e.g., disagreeing with an authority figure). Validation of the DOSPERT showed that participants varied in their risk perceptions and risk preferences across domains.

Nevertheless, in research on risky decisions, domain has been largely overlooked. For example, it is generally understood that adolescents tend to engage in more risky behavior than adults (Arnett, 1992). However, these results are based mainly on health behaviors such as smoking, drunk driving, or unsafe sex (for a review, refer to Albert \& Steinberg, 2011). When it comes to social risks, such as disagreeing with a friend or wearing the wrong color shoes, adolescents appear to be extremely conservative. There is some evidence that adolescents are especially influenced by their peers while making risky decisions (Gardner \& Steinberg, 2005), yet even this research focuses mostly on health or safety risks.

There is even less research focusing on whether older adults distinguish among risk domains, and the existing research tends to be inconclusive and contradictory. These conflicting results may be explained by considering risk domains and examining social risks separately from the more traditional domains. Because older adults tend to have more health problems, they might be especially risk averse for health-related risks. However, for social risks, older adults may be less intimidated by authorities and less concerned that a single social misstep will ruin their lives forever.

Socioemotional selectivity theory (SST) asserts that as individuals age, their social motivations change (Carstensen, 1993). SST suggests that older adults tend to have emotion regulation goals that cause them to be more selective in their social partners. For instance, older adults tend to spend time with more familiar social partners (such as their relatives) rather than new people (Fredrickson \& Carstensen, 1990). This implies that although older adults may have smaller social networks; their networks are stronger and more durable than those of young adults. Therefore, older adults may see socially risky behaviors as less risky. For example, if your relationship is strong, disagreeing with a friend is unlikely to have serious consequences, but if your friend is just one of many less certain relationships, a serious argument could cause it to dissolve.

\section{Risk motivations}

In addition to age differences in risky behavior, there may also be differences in why people choose to take a risk. Imagine that Jack and Jill are offered cocaine at a party. Jack chooses to use the cocaine because he likes it. Jill, on the other hand, does not like cocaine and worries about the possible side effects, but she uses it because all of her friends are doing it. If we only examine behavior, Jack and Jill appear similar, but if we want to try to prevent Jack and Jill from using cocaine, it is important to understand their differing motivations.

In addition, risk perception is not a direct proxy for the likelihood of engaging in risky behavior. Often, studies do not ask participants about actual risk behaviors but rather about how risky they believe that they are; the assumption is that if people believe that behaviors are risky, they are less likely to engage in them. However, although these two concepts are often used interchangeably, they are different. Risk perception refers to one's assessment of how risky a behavior is, whereas risk preference refers to one's inclination to do it. Risk perception clearly plays a role in risk preference; the more risk that one sees in a behavior, the less likely one is to engage in that behavior. The reverse is also true: Many people engage in risky behavior because they underestimate the risk involved.

However, failing to appreciate the risk is not the only reason that people take risks. As in the shower example, there are reasons to engage in risky behavior even when we know it is risky. Some people may enjoy risk and seek dangerous situations such as skydiving or traveling to third-world countries. Other people feel uncomfortable in risky situations, motivating them to avoid them. Sensation-seeking scales measure these individual differences and predict risk taking (e.g. Hoyle, Stephenson, Palmgreen, Pugzles Lorch, \& Donohew, 2002). Returning to our cocaine example, Jack enjoys cocaine and would likely score high on a sensationseeking scale, whereas Jill finds it somewhat unpleasant and would likely score low.

In addition to affective motivations, people may also take or avoid risks in order to gain something or to avoid losing something. For example, people often risk money by investing in risky stocks because they believe that the risk is worth the possibility of gaining more money. People also risk having their hearts broken by proposing marriage, believing that the possibility of being accepted is worth the risk. Patients undergo experimental treatments with severe side effects because the possibility of recovery makes the risk seem justified. In all of these cases, people understand the risks but judge the possible outcomes worthwhile. 


\section{Current studies}

To examine how age affects risk taking across domains, we conducted two surveys of adult participants. Our goals were to determine whether participants had consistent risk preferences across domains, to examine age differences in risk perceptions and preferences across domains, and to identify motivations that might explain these age differences. We asked participants about risk perceptions and preferences in several risk domains (health/safety, social, ethical, environmental, and other). We predicted age differences in risk perception and risk preference for both the social and health/safety domains but in opposite directions. For the social domain, following SST, we predicted that as older adults have strong, durable social networks, they would find risky social behaviors less threatening and would be more likely to engage in them. For the health/safety domain, we predicted the opposite. As older adults develop more health problems, we hypothesized that they would rate health/safety behaviors as more risky and would be less likely to engage in them. We had no specific predictions for the other three domains but included them to collect exploratory data. We also examined motivations for each risky behavior and included personality measures of sensation seeking as well as questions about participants' previous experiences with the risky behaviors in order to create a model of risky decision making across different age groups. We discuss differences in the two surveys in the succeeding texts.

\section{STUDY 1}

\section{Method}

\section{Participants}

Participants $(N=176)$ ranging in age from 18 to 83 years were divided into three age groups: young adults (18-25 years; 15 male subjects, 45 female subjects, $M=19.83, S D=2.34$ ), adults (26 to 59 years (31 male subjects, 48 female subjects, $M=38.15, S D=9.05$ ), and older adults (60 to 83 years (12 male subjects, 25 female subjects, $M=71.05, S D=7.69)$. Most of the young adults $(N=41)$ were recruited from the University of Michigan Department of Psychology subject pool and received course credit for participation. The other young adults $(N=19)$ and the participants in the middle-age group were recruited online through the Amazon Turk website and received $\$ .25$ for their participation. Participants in the older adult group were recruited via telephone from local areas and received $\$ 10.00$ for participating. ${ }^{1}$ The majority of the participants self-defined as Caucasian $(N=134)$, while the rest self-defined as Asian/Asian American $(N=19)$, Black/African-American $(N=14)$, Latino/Hispanic $(N=7)$, and other $(N=2)$. Racial breakdowns were roughly the same for each age group.

\footnotetext{
${ }^{1}$ Although our participants were recruited from different populations, our two main comparison groups (young adults and older adults) were mostly recruited from the local Ann Arbor population. Furthermore, although the subject pool population was more female, no differences were found for our main results between the young adults recruited from Amazon Turk and the young adults recruited from the University of Michigan subject pool.
}

\section{Materials}

Risk items. Forty risky behaviors/situations were chosen across five different risk domains: social risk, health/safety risk, ethical risk, environmental risk, and other risk. Fifteen items were taken from the DOSPERT (Weber et al., 2002), and we created the rest of the items so that risk would apply equally to young and older adults. Although we used some items from the DOSPERT, others were omitted after pretesting with our specific populations as many participants found them unfamiliar and irrelevant to their lives. The domain of recreational risks was not included as older adults do not engage in many of the behaviors included in this domain and most of them would be objectively riskier for the older adults. Financial risks were also omitted because those items did not apply to most of our young adults as our young adults had little experience with either betting or investing. Environmental risks were added as this type of risk is commonly studied but not across different age groups. Finally, our last domain of risks included risks that did not fit in any previously defined domain. Refer to the Appendix for the full list of risk items.

Behavior intention. Participants were asked to rate the likelihood that they would engage in each risky behavior. The behavior intention question was "indicate the likelihood that you would engage in the described activity or behavior if you were to find yourself in that situation," (DOSPERT; Weber et al., 2002). We used this wording so that even participants who had not engaged in the behavior could respond. Participants responded on a 7-point scale from "extremely unlikely" to "extremely likely." Internal consistency for the behavior intention question was acceptable at the .70 level for most of the risk domains: health/safety risk (13 items; $\alpha=.85$ ), ethical risk (six items; $\alpha=.77$ ), and environmental risk (seven items; $\alpha=.83$ ). One item ("moving to a city far away from your family") was omitted from the social risk items to increase reliability to an acceptable level (six items; $\alpha=.70$ ); reliability was low for the seven other risk items $(\alpha=.65)$, which is not surprising as the items were not chosen to be related to each other. Subscales were created for behavior intentions for each of the risk domains using the average of the items in each domain.

Risk perception. The risk perception question asked participants to provide a "gut level assessment of how risky each situation or behavior is" (Weber et al., 2002), with a 7-point response scale ranging from "not at all risky" to "extremely risky." Internal consistency for the risk perception question was acceptable at the .70 level for all five risk domains: social risk (six items; $\alpha=.77$; we omitted the seventh item to be consistent with the intention subscale), health/safety risk (13 items; $\alpha=.88$ ), ethical risk (six items; $\alpha=.81$ ), environmental risk (seven items; $\alpha=.84$ ), and other risk items (seven items; $\alpha=.71$ ). We created subscales for risk perception for each of the risk domains using the average of the items in each domain.

Risk domain. To ensure that our categorizations matched the participants' categorizations, they were asked to label each of the risk items with one of the five risk domains (social, health/safety, ethical, environmental, and other). Participants who chose the "other" category were asked to name the category that best fits the risk item. The majority of participants 
chose the same category as the experimenters (63\%); these agreements were especially high for social risks (72\%), health/safety risks (91\%), and ethical risks (85\%), while agreement was much lower for environmental risks (35\%) and other risks (33\%). Similar percentages were found across age groups. There were no differences in how the young and older adults labeled the risks. Analyses showed no significant differences between the participant-defined risk categories and the experimenter-defined risk categories on age differences in risk perceptions and risk behavioral intentions; the results presented are based on the experimenter-defined categories.

\section{Procedure}

Participants completed the survey either online or in a lab at the University of Michigan. Participants were told that they would be answering a series of questions regarding their thoughts and behaviors about risky situations. The questions were presented in the same order for all participants with the behavior intention questions first, followed by the risk perception questions, and finally the risk domain labeling questions. For each of the questions, the risk items were presented in the same order (as given in the Appendix). The behavior intention questions were asked first because we thought that it would be more likely that risk perceptions would influence the behavioral intentions than the other way around. Participants answered demographic questions at the end of the survey.

\section{Results}

\section{Correlations}

There were significant positive correlations among all of the risk domains on risk intentions across the entire sample (Table 1). However, these correlations ranged from .16 to .78; interestingly, the social risk subscale was least correlated with the other risk domains (ranging from .16 to .34). The high positive correlations suggest that people who tend to engage in risky behavior in one domain also tend to engage in risky behavior in other domains. Likewise, there were significant positive correlations among all of the risk domains on risk perceptions (Table 2). Again, these correlations varied from .19 to .75 , and the social risk subscale tended to be least correlated with the other risk domains. These results indicate that there may also be a general tendency for people who see situations in one domain as risky to perceive high risk in other domains. Finally, Pearson correlations were computed between risk intention and risk perception for each of the five

Table 1. Correlations between risk intention subscales

\begin{tabular}{lcccc}
\hline Domain & $\begin{array}{c}\text { Health/Safety } \\
\text { risk }\end{array}$ & $\begin{array}{c}\text { Ethical } \\
\text { risk }\end{array}$ & $\begin{array}{c}\text { Environmental } \\
\text { risk }\end{array}$ & $\begin{array}{c}\text { Other } \\
\text { risk }\end{array}$ \\
\hline Social risk & $.225^{\mathrm{a}}$ & $.159^{\mathrm{b}}$ & $.340^{\mathrm{a}}$ & $.323^{\mathrm{a}}$ \\
Health/Safety risk & & $.784^{\mathrm{a}}$ & $.516^{\mathrm{a}}$ & $.615^{\mathrm{a}}$ \\
Ethical risk & & & $.407^{\mathrm{a}}$ & $.542^{\mathrm{a}}$ \\
Environmental risk & & & & $.588^{\mathrm{a}}$ \\
\hline Note. & & & & \\
${ }^{\mathrm{a} p} p<.01$, & & & \\
$\mathrm{b} p<.05$. & & & & \\
$p$ & & &
\end{tabular}

Table 2. Correlations between risk perception subscales

\begin{tabular}{lcccc}
\hline Domain & $\begin{array}{c}\text { Health/Safety } \\
\text { risk }\end{array}$ & $\begin{array}{c}\text { Ethical } \\
\text { risk }\end{array}$ & $\begin{array}{c}\text { Environmental } \\
\text { risk }\end{array}$ & $\begin{array}{c}\text { Other } \\
\text { risk }\end{array}$ \\
\hline Social risk & $.299^{\mathrm{a}}$ & $.272^{\mathrm{a}}$ & $.185^{\mathrm{a}}$ & $.475^{\mathrm{a}}$ \\
Health/Safety risk & & $.748^{\mathrm{a}}$ & $.705^{\mathrm{a}}$ & $.724^{\mathrm{a}}$ \\
Ethical risk & & & $.531^{\mathrm{a}}$ & $.626^{\mathrm{a}}$ \\
Environmental risk & & & & $.546^{\mathrm{a}}$ \\
\hline Note. & & & & \\
${ }^{\mathrm{a}} p<.01$. & & & & \\
& & & &
\end{tabular}

risk domains. There were significant negative correlations $(p s<.01)$ between risk intentions and risk perception in each domain. The correlations were high for both the health $(r=-.59)$ and ethical $(r=-.56)$ domains but lower for the social $(r=-.37)$, environmental $(r=-.28)$, and other $(r=-.48)$ domains.

\section{Group differences}

We sampled from three age groups representing three different stages of life. As these three groups were specifically targeted, our age distribution was not continuous. Therefore, we analyzed the data using age as a categorical variable with a specific contrast comparing young adults to the older adults. The pattern of results remains the same when analyzing the data with age as a continuous variable. ${ }^{2}$ The effects of age on risk intention and perception were examined using univariate ANOVAs with age group as the independent variable and risk intention and perception as the dependent variables. For each dependent variable, we report both the omnibus test and the planned linear contrast comparing young and old (i.e., $-1,0,1$ ); for completeness, we report all three pairwise tests. Sample sizes varied slightly across the intention and perception subscales because of missing data; $N \mathrm{~s}$, means, and standard deviations are reported in Table 3.

Health/Safety risks. For the health/safety risk domain, as predicted, age had a significant omnibus effect on risk perception $(F(2,164)=3.45, p<.05$; refer to Figure 1$)$. Pairwise planned contrasts showed that older adults $(M=5.55$, $S D=1.19)$ rated health/safety risks as significantly more risky than young adults $(M=4.99, S D=.85 ; p<.05)$ or adults $(M=5.08, S D=1.02 ; p<.05)$. Young adults and adults did not differ on perceptions of health/safety risks. Age also had a significant omnibus effect on risk intentions for health/safety risks $(F(2,165)=15.85, p<.01)$. Specifically, pairwise planned contrasts demonstrated that young adults $(M=3.18, S D=1.05)$ were significantly more likely to engage in risky health or safety behaviors than adults

\footnotetext{
${ }^{2}$ We mean centered age and entered both linear and quadratic predictors. Across all 10 regressions, the linear predictor of age yielded the same statistical conclusion as the linear contrast in the three-group ANOVA (i.e., young versus older adults). In two cases (ethical and other risk perceptions), the quadratic term in the three-group ANOVA was statistically significant, bu the quadratic predictor in the regression was not. We do not make use of quadratic trends in this paper, focusing on pairwise differences between age groups, so we do not consider the regression results using continuous age.
} 
Table 3. Risk perception and risk intention means for all domains (Study 1)

\begin{tabular}{|c|c|c|c|c|c|c|}
\hline & & Health/Safety risk & Ethical risk & Social risk & Environmental risk & Other risk \\
\hline \multirow[t]{9}{*}{ Risk perceptions } & \multirow[t]{3}{*}{ Young adults } & $M=4.99$ & $M=4.89$ & $M=2.83$ & $M=5.42$ & $M=4.65$ \\
\hline & & $S D=.85$ & $S D=1.07$ & $S D=1.02$ & $S D=.95$ & $S D=.88$ \\
\hline & & $N=59$ & $N=60$ & $N=60$ & $N=59$ & $N=59$ \\
\hline & \multirow[t]{3}{*}{ Adults } & $M=5.08$ & $M=4.97$ & $M=2.48$ & $M=5.49$ & $M=4.33$ \\
\hline & & $S D=1.02$ & $S D=1.21$ & $S D=.99$ & $S D=1.06$ & $S D=1.03$ \\
\hline & & $N=76$ & $N=79$ & $N=79$ & $N=78$ & $N=76$ \\
\hline & \multirow[t]{3}{*}{ Older adults } & $M=5.55$ & $M=5.77$ & $M=2.45$ & $M=5.56$ & $M=4.76$ \\
\hline & & $S D=1.19$ & $S D=1.16$ & $S D=.94$ & $S D=1.39$ & $S D=1.11$ \\
\hline & & $N=32$ & $N=31$ & $N=36$ & $N=33$ & $N=35$ \\
\hline \multirow[t]{9}{*}{ Risk intentions } & \multirow[t]{3}{*}{ Young adults } & $M=3.18$ & $M=2.58$ & $M=4.57$ & $M=2.71$ & $M=2.84$ \\
\hline & & $S D=1.06$ & $S D=1.07$ & $S D=.96$ & $S D=1.04$ & $S D=1.08$ \\
\hline & & $N=60$ & $N=60$ & $N=58$ & $N=60$ & $N=60$ \\
\hline & \multirow[t]{3}{*}{ Adults } & $M=2.77$ & $M=1.97$ & $M=4.87$ & $M=2.95$ & $M=3.03$ \\
\hline & & $S D=1.19$ & $S D=1.08$ & $S D=1.13$ & $S D=1.17$ & $S D=1.04$ \\
\hline & & $N=76$ & $N=78$ & $N=79$ & $N=76$ & $N=76$ \\
\hline & \multirow[t]{3}{*}{ Older adults } & $M=1.85$ & $M=1.51$ & $M=4.88$ & $M=2.36$ & $M=2.53$ \\
\hline & & $S D=.82$ & $S D=.68$ & $S D=.95$ & $S D=.99$ & $S D=1.00$ \\
\hline & & $N=32$ & $N=34$ & $N=35$ & $N=32$ & $N=35$ \\
\hline
\end{tabular}

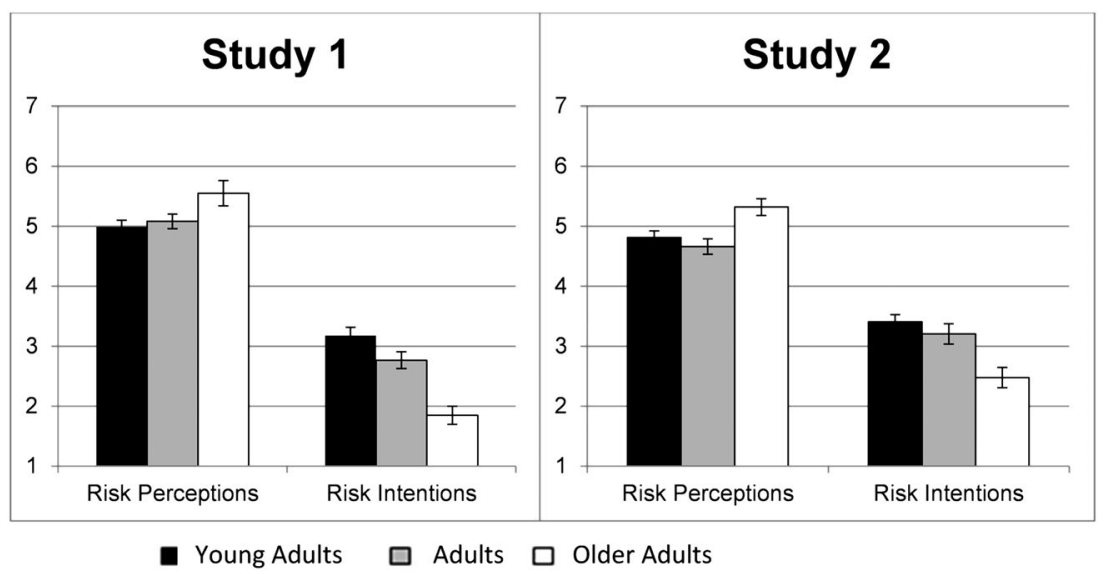

Figure 1. Risk perceptions and behavioral intentions for health/safety risks across the three age groups. Error bars represent one standard error above and below the mean

$(M=2.77, S D=1.19 ; p<.05)$ or older adults $(M=1.85$, $S D=.82 ; p<.01)$. Older adults were also significantly less likely to engage in these risky behaviors than the adults $(p<.01)$.

Ethical risks. The ethical risk domain resembled the health/safety domain for risk intention (Figure 2). Age had a significant omnibus effect on risk perception $(F(2,169)$ $=6.77, p<.01)$. Pairwise planned contrasts showed that the older adults $(M=5.77, S D=1.16)$ rated the ethical risk items as significantly more risky than the adults $(M=4.97$, $S D=1.21 ; p<.01)$ or the young adults $(M=4.89, S D=1.07$; $p<.01)$. Adults and young adults did not differ. Age also had a significant omnibus effect on risk intentions $(F(2,169)$ $=13.08, p<.01)$. As in the health/safety domain, pairwise planned contrasts demonstrated that the young adults $(M=2.58, S D=1.07)$ were significantly more likely to say that they would engage in the risky behaviors than the adults $(M=1.97, S D=1.08 ; p<.01)$ or the older adults $(M=1.51$, $S D=.68 ; p<.01)$. The difference between the adults and older adults for ethical risk intentions was also significant $(p<.05)$.
Social risks. For risk perception in the social risk domain, the opposite pattern occurred (Figure 3). The overall effect on the perception of social risks did not reach statistical significance $(F(2,172)=2.59, p=.08)$. Pairwise planned contrasts illustrated that young adults $(M=2.83, S D=1.02)$ rated the social risk items as significantly more risky than the adults $(M=2.48, S D=.99 ; p<.05)$, but the comparison with older adults did not reach statistical significance $(M=2.45$, $S D=.94 ; p=.07)$. For the risk intention questions, age did not have a significant effect on risk intention $(p=.21)$.

To compare the pattern observed in the social domain with that in the health/safety and ethical domains, we conducted a $5 \times 2 \times 3$ ANOVA with risk domain and risk perceptions/intentions as within-subjects factors and age group as a between-subjects factor. We tested the three-way interaction between a contrast over domain that compared health/safety and ethical with social (contrast weights: 1 1-2 00 ), a contrast over age group that compared young with older adults (contrast weights: $10-1$ ), and the standard (1-1) contrast over the two-level perception/intention factor. This three-way interaction effect was statistically significant, $F(1,150)=26.65, p<.001$. 


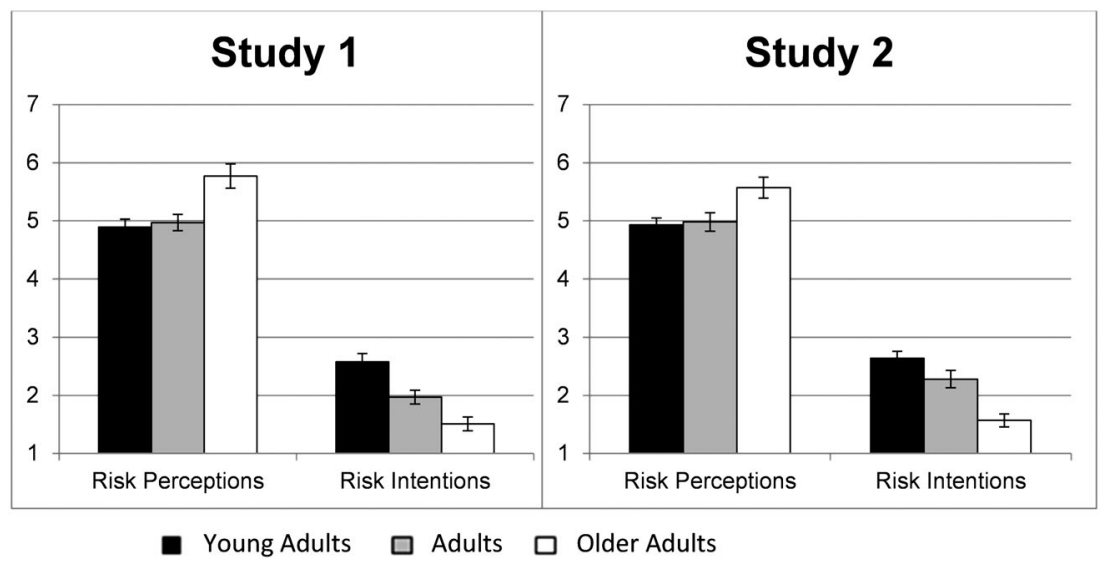

Figure 2. Risk perceptions and behavioral intentions for ethical risks across the three age groups. Error bars represent one standard error above and below the mean

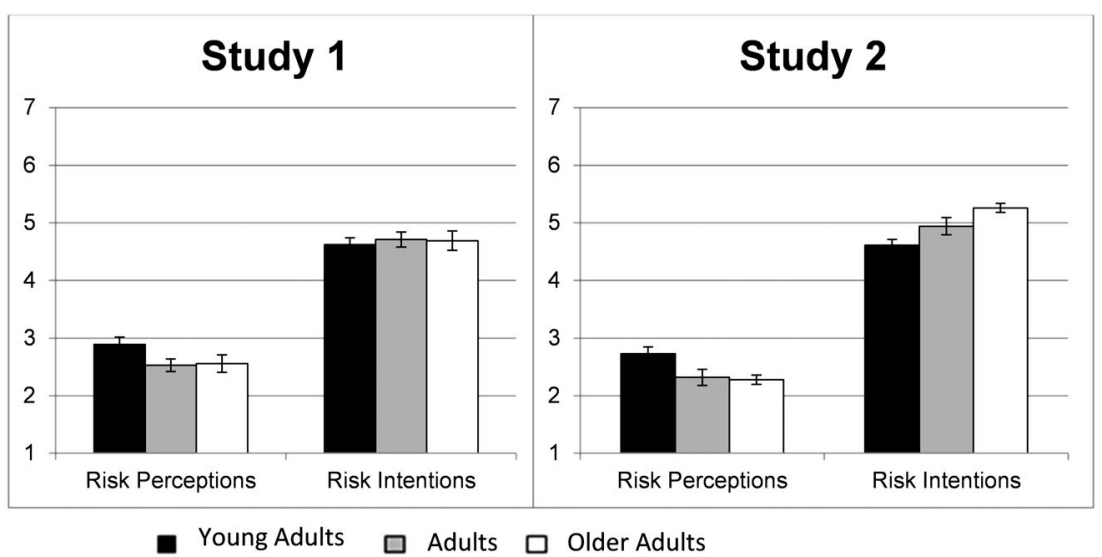

Figure 3. Risk perceptions and behavioral intentions for social risks across the three age groups. Error bars represent one standard error above and below the mean

The last two risk domains, environmental risk and other risk, showed no age differences in either risk intentions or perceptions. Table 3 presents means for risk perceptions and risk intentions by domain.

\section{Discussion}

Overall, participants showed a general risk perception and risk preference across domains: If they perceived risk in one domain, they also perceived risk in others, and if they were risk seeking in one domain, they tended to be risk seeking in other domains. However, age differences varied by domain. For health/safety and ethical domains, older participants perceived more risk and rated themselves as less likely to engage in the risky behaviors than young adults, while for social risks, older participants perceived similar amounts of risk as young adults and rated intentions at levels similar to the young adults.

Overall, the social risks were perceived as less risky than the health/safety and ethical risks. However, comparing the riskiest social risk item ("disagreeing with an authority figure on a major issue") and the least risky health/safety risk item ("drinking out of the same glass as someone else"), the same patterns occurred. Although these results indicate that our effects are most likely not driven by overall risk levels (rather than risk domain), we will discuss this possibility further in the general discussion.
The results for the environmental and "other" risk domains did not show any differences between the age groups. Many of the environmental risks were labeled by our participants as health/safety risks, but they did not show the same age differences. However, one key difference between the environmental risks and the other health/safety risks is that the environmental risks were all situations that were more difficult to control. The effects of controllability on age differences will be discussed further in the general discussion.

The "other" risk domain did not show overall differences because the individual items were too unrelated and did not have consistent effects. However, several of the individual items did show age differences. For instance, the older adults reported lower intentions of driving over the speed limit than the young adults, while the opposite pattern occurred for the item involving being a victim of violent crime. Some of the other items could also be interpreted in different ways. For example, driving over the speed limit could be seen as a health/safety risk as it might increase the likelihood of being in an accident, or it could be seen as a financial risk as it might also increase the likelihood of getting a speeding ticket. However, because there were no consistent age differences in either domain, both environmental and other risk domains were dropped for Study 2 .

We conducted Study 2 to explore one explanation for the age differences found in Study 1. We hypothesized that older 
and younger participants may appraise the costs and benefits associated with the risks differently. Traditionally, decisionmaking models propose that decisions about risk involve tradeoffs between the perceived benefits and the perceived risks of the decision (Weber, 1998). If the possible benefits outweigh the risks, the riskier choice is picked, whereas if the risks outweigh the benefits, the safer choice is made. Risky decision making also varies with whether the risky situation involves a gain or a loss. Generally, "losses loom larger than gains," and people tend to make riskier choices in order to avoid losses than to realize gains (Kahneman \& Tversky, 1979). Weller, Levin, and Denburg (2011) examined risky loss scenarios separately from risky gain scenarios and found that although risk taking decreased for risky gains across the life span, risk taking for risky losses remained fairly consistent. If risks in some domains are more related to losses than to gains, this might explain the age differences found in Study 1. Additionally, one limitation to Study 1 was that the majority of our sample was female subjects, so in Study 2, we sought a more equal gender distribution.

For Study 2, we examined two types of benefits, risk enjoyment and concrete gains, and two types of costs, risk unpleasantness and concrete losses. We predicted that compared with the young adults, older adults would rate the health/safety and ethical risks as being less enjoyable, more unpleasant, less likely to cause gains, and more likely to cause losses. We also predicted that the older adults would find the social risks to be more enjoyable, less unpleasant, more likely to cause gains, and less likely to cause losses than the young adults.

\section{STUDY 2}

\section{Method \\ Participants}

Participants $(N=182)$ ranging in age from 18 to 83 years were divided into three age groups: young adults (18-25 years; 39 male subjects, 41 female subjects, $M=20.19, S D=2.35$ ), adults (26 to 59 years; 26 male subjects, 34 female subjects, $M=34.67, S D=8.87$ ), and older adults (60 to 83 years; 18 male subjects, 24 female subjects, $M=69.40, S D=6.47)$. Most of the young adults $(N=48)$ were recruited from the University of Michigan Department of Psychology subject pool and received course credit for participation; the other young adults $(N=22)$ and the participants in the middle-age group were recruited online through the Amazon Turk website and received $\$ .25$ for their participation. ${ }^{3}$ Participants in the older adult group were recruited from a shared older adult database at the University of Michigan via telephone and received $\$ 10.00$ for participating. The majority of the participants selfdefined as Caucasian $(N=142)$, while the rest self-defined as Asian/Asian American $(N=17)$, Black/African-American $(N=11)$, Latino/Hispanic $(N=11)$, and other $(N=1)$.

\footnotetext{
${ }^{3}$ Again, no differences were found for our main results between the young adults recruited from Amazon Turk and the young adults recruited from the University of Michigan subject pool.
}

\section{Materials}

Risk items. Fifteen risky behaviors/situations were chosen from the original forty items in Study 1 (refer to starred items in the Appendix). For Study 2, we used the five risk items showing the strongest age effect for each of the three risk domains. When Study 1 was reanalyzed using only the 15 most effective items, the pattern of statistically significant results remained the same.

Behavior intention and risk perception. As in Study 1, participants rated the likelihood that they would engage in each behavior as well as its perceived riskiness. Internal consistency for the risk intention question was low for two of the risk domains: social risk (five items; $\alpha=.57$ ) and health/safety risk (five items; $\alpha=.62$ ), but acceptable at the .70 level for ethical risk (five items; $\alpha=.70$ ). Internal consistency for the risk perception question was acceptable at the .70 level for the two risk domains: social risk (five items; $\alpha=.74$ ) and ethical risk (five items; $\alpha=.78$ ). Internal consistency was lower for the health/safety domain (five items; $\alpha=.64$ ). Subscales were created for behavior intention and risk perception for each of the risk domains using the average of the items in each domain.

Risk motivations. To identify the reasons that people choose to engage in risky behaviors in different domains, participants were asked whether each of the following factors influenced their decisions: whether they would find the behavior enjoyable, whether they would find the behavior unpleasant, whether they thought that they might gain something from the behavior, and whether they thought that they might lose something. From these data, four subscales were created: (i) an enjoyment subscale ranging from 0 to 5 in which 0 indicated that the participant did not enjoy any of the risky behaviors in that domain and 5 indicated that the participant enjoyed all of them; (ii) an unpleasantness subscale using similar methods; (iii) a gain subscale ranging from 0 to 5 in which 0 indicated that the participant would not gain anything from any of the risky behaviors in that domain and 5 indicated that the participant would gain something from each of the risky behaviors in that domain; and (iv) a loss subscale ranging from 0 to 5 in which 0 indicated that the participant would not lose anything by engaging in any of the risky behaviors in that domain and 5 indicated that the participant lose something by engaging in each of them.

Participants also rated how enjoyable/unpleasant it was on a 5-point scale ranging from "not at all enjoyable (or unpleasant)" to "extremely enjoyable (or unpleasant)" and were given an open-ended question where they identified what they would gain or lose and then rated the likelihood of gaining or losing it on a 7-point scale ranging from "extremely unlikely" to "extremely likely."

Past behavior. Participants were asked whether they had engaged in the risky behavior in the past. Possible responses for this question were: "never engaged in this behavior," "engaged in this behavior in the past year," and "engaged in this behavior (not including the past year)." Participants also indicated whether they ever had the opportunity to engage in this behavior. 
Sensation-seeking scales. We included two sensation-seeking scales: the Brief Sensation-Seeking Scale (BSSS) (Hoyle et al., 2002) and the Need Inventory for Sensation Seeking (NISS) (Roth \& Hammelstein, 2012). The BSSS (eight items, $\alpha=.83$ ) focuses on specific behaviors (e.g., "I would like to try bungee jumping"), while the NISS (17 items, $\alpha=.86$ ) asks more general questions (e.g., "I like to find myself in situations which make my heart beat faster").

\section{Procedure}

The procedure for Study 2 was the same as in Study 1. Participants completed the survey either online or in a lab at the University of Michigan. Participants were told that they would be answering a series of questions regarding their thoughts and behaviors about risky situations. The questions were presented in the same order for all participants with the behavior intention questions occurring first, followed by the risk perception questions, the risk factor questions, and then the sensation-seeking scales. The risk items were always presented in the same order, alternating between each risk domain. Participants answered demographic questions at the end of the survey.

\section{Results \\ Correlations}

Similar to Study 1, all of the risk domains for risk perceptions were correlated across the entire sample. Health/Safety and ethical risk perceptions were highly correlated $(r=.74$, $p<.01)$; social risks had lower correlations with health/safety risks $(r=.31, p<.01)$ and ethical risks $(r=.27, p<.01)$. Health/Safety and ethical risk intentions were also highly correlated $(r=.61, p<.01)$. However, social risk intentions had a low correlation to health/safety risk intentions $(r=.15, p=.05)$ and were not significantly correlated with ethical risk intentions $(r=.10, p>.05)$. These correlations support the idea that health/safety and ethical risks are related to each other, whereas social risks appear to be different. We also found significant negative correlations between risk perceptions and risk intentions for all three domains ranging from -.44 to -.56 indicating that risk perception plays a role in whether people are likely to report that they would engage in risky behavior.

\section{Sensation seeking}

Age differences on the two sensation-seeking scales were examined using univariate ANOVAs with age group as the independent variable and the sensation-seeking scales as the dependent variables. Age had a significant omnibus effect on both the BSSS $(F(2,169)=20.78, p<.01)$ and the NISS $(F(2,169)=9.79, p<.01)$. As predicted, for the BSSS, young adults $(M=25.73, S D=6.09)$ scored significantly higher than the adults $(M=21.31, S D=6.38 ; p<.01)$ and the older adults $(M=18.45, S D=4.95 ; p<.01)$. Older adults also scored significantly lower than the adults $(p<.05)$. For the NISS, young adults $(M=50.88, S D=7.60)$ also scored significantly higher than the adults $(M=45.02, S D=9.55 ; p<.01)$ and the older adults $(M=45.56, S D=7.67 ; p<.01)$. However, adults and older adults did not differ on their NISS scores.

\section{Age differences on risk intentions and risk perceptions}

The patterns of age differences for risk perceptions and risk intentions mostly replicated the results of Study 1 showing that older adults tended to see more risk and rate themselves as less likely to engage in risky behavior for health/safety and ethical risks but not for social risks. The effects of age on risk perceptions and risk intentions were examined using univariate ANOVAs with age group as the independent variable and risk intention and risk perception as the dependent variables.

Health/Safety risks. Replicating Study 1, for the health/safety risk domain, age had a significant omnibus effect on risk perceptions $(F(2,174)=6.01, p<.01)$ and intentions $(F(2,175)=8.60$, $p<.01$; refer to Figure 1). Pairwise planned contrasts showed that older adults $(M=5.32, S D=.97)$ rated health/safety risks as more risky than young adults $(M=4.81, S D=.94 ; p<.01)$ and adults $(M=4.66, S D=.97 ; p<.01)$. Pairwise planned contrasts also showed that older adults $(M=2.48, S D=1.02)$ were significantly less likely to say that they would engage in risky health or safety behaviors than young adults $(M=3.41$, $S D=1.05 ; p<.01)$ and adults $(M=3.21, S D=1.31 ; p<.01)$. No differences were found between adults and young adults for risk perceptions or intentions.

Ethical risks. As in Study 1, the ethical risk domain resembled the health/safety domain for risk intention and risk perception (Figure 2). Age had a significant effect on both risk perceptions $(F(2,174)=4.75, p=.01)$ and risk intentions $(F(2,171)=13.18, p<.01)$. Pairwise planned contrasts demonstrated that the older adults $(M=5.57, S D=1.12)$ rated the ethical risk items as significantly more risky than the young adults $(M=4.93, S D=1.02 ; p<.01)$ and the adults $(M=4.98$, $S D=1.24 ; p=.01)$. Pairwise planned contrasts also showed that the young adults $(M=2.64, S D=1.10)$ were significantly more likely to say that they would engage in the risky behaviors than the adults $(M=2.28, S D=1.17 ; p<.01)$ and the older adults $(M=1.57, S D=.71 ; p<.01)$. Older adults were also significantly less likely to say that they would engage in the risky behaviors than the adults $(p<.05)$.

Social risks. For the social risk domain, the results were reversed (Figure 3). Age had a significant effect on risk perception in the social domain $(F(2,172)=3.82, p<.05)$. Young adults $(M=2.73, S D=1.06)$ rated the social risk items as significantly more risky than adults $(M=2.32, S D=1.07$; $p<.05)$ and older adults $(M=2.28, S D=.77 ; p<.05)$. Age also had a significant effect on risk intention $(F(2,174)$ $=5.67, p<.01)$ : Young adults $(M=4.61, S D=.91)$ were significantly less likely to say that they would engage in social risks than older adults $(M=5.26, S D=.95 ; p<.05)$, but they were not significantly different in their intentions to engage in social risks than the adults $(M=4.94, S D=1.15 ; p=.06)$. No differences were found between the adults and older adults for either risk intention or risk perception.

As in Study 1, we conducted a test of interaction using a $3 \times 2 \times 3$ ANOVA with risk domain and risk 
perceptions/intentions as within-subjects factors and age group as a between-subjects factor with contrasts to compare the age difference pattern seen in the health/safety and ethical risks with the pattern found in the social risks. This interaction effect comparing young and older adults was statistically significant, $F(1,161)=38.79, p<.01$.

\section{Motivational factors}

The enjoyment, unpleasantness, gain, and loss subscales were analyzed for differences among the age groups in reasons for engaging in the risky behaviors. As older adults rated themselves less likely to engage in the health/safety and ethical risks, we expected that they would also rate these risks as less enjoyable, more unpleasant, less likely to cause gains, and more likely to cause losses than the young adults. We also expected that the older adults would find the social risks more enjoyable, less unpleasant, more likely to cause gains, and less likely to cause losses than the young adults.

Health/Safety risks. For the health/safety domain, as predicted, age had a significant omnibus effect on enjoyment $(F(2,179)=8.30, \quad p<.01)$ and gain $(F(2,179)=6.49$, $p<.01$; refer to Table 4$)$. Older adults $(M=.33, S D=.57)$ were less likely to enjoy the risky health/safety behaviors than young adults $(M=1.00, S D=.95 ; p<.01)$ or adults $(M=1.10$, $S D=1.04 ; p<.01)$. Additionally, the young adults $(M=.69$, $S D=.84)$ stated that they were more likely to gain something by engaging in the risky behaviors than adults $(M=.42$, $S D=.87 ; p<.05)$ or older adults $(M=.17, S D=.44 ; p<.01)$. Age also had a significant effect on unpleasantness $(F(2,179)=3.77, p<.05)$. However, the effect contradicted our predictions as young adults $(M=2.70, S D=1.22)$ rated the health/safety risks as more unpleasant than adults $(M=2.20$,
$S D=1.52 ; p<.05)$ or older adults $(M=2.02, \quad S D=1.67$; $p<.01)$. No age differences were found for perceived loss.

Ethical risks. For ethical risks, the pattern was again similar to the health/safety domain. Age had a significant effect on the enjoyment $(F(2,179)=5.59, p<.01)$ and gain subscales $(F(2,179)=8.74, p<.01)$. Older adults $(M=.21, S D=.65)$ rated the ethical risks as less enjoyable than the young adults $(M=.66, S D=.86 ; p<.01)$ or adults $(M=.77, S D=.98$; $p<.01)$. Older adults $(M=.55, S D=1.11)$ also said that they were less likely to gain something than the young adults $(M=1.74$, $S D=1.54 ; p<.01)$ or adults $(M=1.35, S D=1.66 ; p<.01)$. No age differences were found for unpleasantness or loss.

Social risks. In the social domain, young adults $(M=1.18$, $S D=1.19$ ) were less likely to enjoy socially risky behavior than adults $(M=1.63, S D=1.48 ; p<.05)$, while older adults $(M=1.31, S D=1.20)$ did not differ from either young adults or adults. Age also had a significant effect on unpleasantness $(F(2,179)=10.31, p<.01)$ and losses $(F(2,179)=3.55$, $p<.05)$. Young adults $(M=2.19, S D=1.44)$ rated socially risky behaviors as more unpleasant than adults $(M=1.50$, $S D=1.27 ; p<.01)$ or older adults $(M=1.07, S D=1.31$; $p<.01)$ and said that they were $(M=2.08, S D=1.52)$ more likely to lose something by engaging in socially risky behavior than older adults $(M=1.36, S D=1.48 ; p=.01)$.

\section{Discussion}

The correlations across risk domains suggest a general risk trait for both risk perceptions and behavioral intentions. In both studies, we found significant correlations among domains for both risk perceptions, suggesting that people who see risk in one domain tend to see risk in other domains as

Table 4. Risk motivation means for all domains (Study 2)

\begin{tabular}{|c|c|c|c|c|}
\hline Risk domain & Motivation & Young adults & Adults & Older adults \\
\hline \multirow[t]{8}{*}{ Health/Safety risks } & \multirow[t]{2}{*}{ Enjoyment } & $M=1.00$ & $M=1.10$ & $M=0.33$ \\
\hline & & $S D=.95$ & $S D=1.04$ & $S D=.57$ \\
\hline & \multirow[t]{2}{*}{ Unpleasantness } & $M=2.70$ & $M=2.20$ & $M=2.02$ \\
\hline & & $S D=1.22$ & $S D=1.52$ & $S D=1.67$ \\
\hline & \multirow[t]{2}{*}{ Gain } & $M=.69$ & $M=.42$ & $M=.17$ \\
\hline & & $S D=.84$ & $S D=.87$ & $S D=.44$ \\
\hline & \multirow[t]{2}{*}{ Loss } & $M=3.34$ & $M=3.62$ & $M=3.60$ \\
\hline & & $S D=1.55$ & $S D=1.32$ & $S D=1.21$ \\
\hline \multirow[t]{8}{*}{ Ethical risks } & \multirow[t]{2}{*}{ Enjoyment } & $M=.66$ & $M=.77$ & $M=.21$ \\
\hline & & $S D=.86$ & $S D=.98$ & $S D=.65$ \\
\hline & \multirow[t]{2}{*}{ Unpleasantness } & $M=2.64$ & $M=2.23$ & $M=2.36$ \\
\hline & & $S D=1.54$ & $S D=1.74$ & $S D=1.83$ \\
\hline & \multirow[t]{2}{*}{ Gain } & $M=1.74$ & $M=1.35$ & $M=.55$ \\
\hline & & $S D=1.54$ & $S D=1.66$ & $S D=1.11$ \\
\hline & \multirow{2}{*}{ Loss } & $M=3.23$ & $M=3.63$ & $M=3.36$ \\
\hline & & $S D=1.65$ & $S D=1.54$ & $S D=1.64$ \\
\hline \multirow[t]{8}{*}{ Social risks } & \multirow[t]{2}{*}{ Enjoyment } & $M=1.18$ & $M=1.63$ & $M=1.31$ \\
\hline & & $S D=1.19$ & $S D=1.48$ & $S D=1.20$ \\
\hline & \multirow[t]{2}{*}{ Unpleasantness } & $M=2.19$ & $M=1.50$ & $M=1.07$ \\
\hline & & $S D=1.44$ & $S D=1.27$ & $S D=1.31$ \\
\hline & \multirow[t]{2}{*}{ Gain } & $M=2.90$ & $M=2.60$ & $M=2.93$ \\
\hline & & $S D=1.66$ & $S D=1.66$ & $S D=1.61$ \\
\hline & \multirow[t]{2}{*}{ Loss } & $M=2.08$ & $M=1.67$ & $M=1.36$ \\
\hline & & $S D=1.52$ & $S D=1.37$ & $S D=1.48$ \\
\hline
\end{tabular}


well and for risk intentions, suggesting that people generally engage in or avoid risky behavior across the board. However, the size of the correlations varied indicating that some risk domains may be more related than others. We also found age differences in the sensation-seeking scales such that older adults tended to score lower than the young adults. These results suggest that general risk preferences may not be stable across the life span.

Health/Safety risks and ethical risks showed high correlations and similar age differences suggesting that they may be highly related. Although these domains may seem different at first glance, there are similarities. Morality is inherent in ethical risks; there is an obvious "right" way and a "wrong" way to behave. However, the risky health behavior items also contain some underlying morality concerns. Unhealthy lifestyles, including behaviors such as smoking, eating unhealthy foods, and practicing unsafe sexual behavior, may appear to harm only the person doing them, but these behaviors can also be interpreted as harming others; for instance, second-hand smoke may cause lung cancer, unsafe sex can spread sexually transmitted disease, and unhealthy behaviors lead to rising health care costs. Unhealthy behaviors are associated with vice, while healthy behaviors are seen as virtuous (Leichter, 1997). On the other hand, the risky social behaviors are morally neutral. Although it might be rude to talk back to an authority figure or disagree with a friend, whether it is right depends on the circumstances.

Health risks and environmental risks also show relatively high correlations, although health risks showed age differences, while environmental risks did not. These high correlations make sense as environmental risks could be considered a subcategory of health risks; one's health is at risk in risky environments. However, they differ from the other health/safety items in how much control one has over taking the risks. Although it is possible to avoid environmental risks (e.g., buying organic food to avoid pesticides), some are unavoidable. This lack of control also affects the morality of the behaviors: If people get lung cancer after smoking for 30 years, it is considered their fault, but if they get lung cancer from second-hand smoke, they are considered unfortunate rather than blameworthy.

However, even assuming some general risk tendencies, there is variability between domains. Whether older adults are more risk averse than young adults depends on the kind of risk. In both Study 1 and Study 2, older adults perceived more health and safety risks and rated themselves as less likely than young people to engage in risky behaviors in these domains. However, in the social domain, the pattern was reversed: Older adults actually perceived less risk and rated themselves as more likely to engage in the risky behaviors than the young adults, although the latter effect only appeared in Study 2 . These results suggest that risk perceptions and risk preferences are highly dependent on domain, and results from one domain may not generalize.

Our findings may explain the conflicting results in this field. Most experiments focus solely on risks in a single domain (Mather, 2006). If risk attitudes are domain dependent, then a study that examines risk in one domain may have different results than a study that examines a risk in a different domain. In other words, a study on health/safety risks may not generalize to social or even ethical risks.
Our studies also investigated the role of motives. Risk-return models examine tradeoffs between the perceived benefits and risks in order to decide on the best course of action (Weber, 1998). These models assume that people weigh the benefit that they would receive for engaging in a risky behavior against the risk and might provide an explanation for the age differences that we found. In Study 2, we measured benefits and risks including enjoyment, unpleasantness, potential losses, and potential gains. Older adults rated health/safety and ethical risky behaviors as less enjoyable and less likely to cause gains than young adults, suggesting that the older adults refrain from taking health/safety risks because they see fewer benefits. Older adults also rated socially risky behaviors as less unpleasant and less likely to cause losses than young adults, indicating that the older adults see more benefits and less risk in risky social behaviors than their younger counterparts.

In addition to motives, we also included personality measures examining preferences for sensation seeking. On both the BSSS and the NISS, the young adults scored significantly higher than the adults and older adults indicating that young adults may have a general tendency for thrill seeking. In order to test whether our results were driven solely by sensation seeking, we reran our analyses using the sensationseeking data as covariates. We found that sensation seeking explained some but not all of the variance. Specifically, including the sensation-seeking data eliminated the age effects in the health/safety domain but not the age effects in the social domain. These results provide further evidence of differences between these domains.

\section{Limitations}

One limitation to our studies is that they used self-report for both behavior and motives. To compare a variety of risk domains, we wanted measures of many different risks, which ruled out the measurement of actual behaviors. Self-reports of behavior can be somewhat unreliable especially when asking about undesirable behavior such as risky behavior. Although we believe that it is unlikely that social desirability factors influence older and younger adults differently, it is possible that participants may have generally underestimated their propensity for risky behavior or the potential benefits (or enjoyment) that they might receive from engaging in the risky behavior. It is also possible that some health/safety risky situations may be seen as more socially desirable for young adults than older adults (e.g., drinking five or more alcoholic drinks). Another limitation is that there could have been order effects because all participants saw the items in the same order. We believe that while this might have increased or decreased risk perceptions or behavioral intentions for individual items, it is unlikely to have influenced the age effects especially as participants in Study 2 saw the items in a different order. Additionally, sample sizes across the age groups differed, most noticeably that the older adult samples were smaller than the young adult and adult samples.

One final limitation is that overall our social risky behaviors were rated as less risky than the health/safety or ethical risky behaviors. This is potentially problematic as it 
is possible that the age differences seen between domains could be because of risk level rather than domain. We examined this possibility by testing individual items within the risk domains. We compared the social risk item that was rated as most risky $(M=3.76, S D=1.61$; disagreeing with an authority figure on a major issue) and the health/safety item that was rated as least risky $(M=3.13, S D=1.59$; drinking out of the same glass as someone else). For the social risk item, older adults $(M=5.20, S D=1.64)$ were significantly more likely to say that they would engage in the behavior than the young adults $(M=3.94, S D=1.63 ; t(177)=-3.66$, $p<.01)$. For the health risk item, older adults $(M=3.37$, $S D=1.87$ ) were significantly less likely to say that they would engage in the behavior than the young adults $(M=4.76, S D=1.86 ; t(175)=3.61, p<.01)$. This shows that we are finding opposite patterns in behavioral intentions across domain even with moderate risks in both domains. Additionally, risks in the environmental and other risk domains showed similar risk levels as the health/safety and ethical domains, yet we did not find any age differences in these domains, indicating that our effects are not completely driven by differences in risk levels.

\section{IMPLICATIONS AND FUTURE DIRECTIONS}

Although it is generally believed that older adults avoid risks, our research suggests that this depends on the risk domain. In our studies, older adults were less risk seeking in health/safety and ethical domains but more risk seeking for social risks, suggesting that people do not become more risk averse as they age but rather that the domain that they worry about may change. Young healthy adults may see health and safety risks as more enjoyable and more likely to provide them with benefits (e.g., looking cool). For example, when asked what would be gained by "consuming five or more alcoholic drinks in a single evening," one young participant wrote "friends due to lower inhibitions." Thus, this participant is willing to take a health risk for the possibility of a social gain. In the social risk domain, young adults see themselves as having more to lose by taking risks. In describing what might be lost by "going to a social event by yourself," one young participant said "social status as being seen as having no friends." Again, what dictates the behavior of the young adult participants seems to be a preoccupation with social relationships. As young adults tend to have less stable social relationships than older adults, it seems reasonable that they should be more concerned with establishing themselves socially.

On the other hand, older adults tend to have more established social networks but increasing health concerns. Therefore, older adults may be more concerned with physical precautions and less willing to take risks that might result in injury. Older adults said that they were less likely to enjoy health risks or to gain something from engaging in the risky behaviors. They also saw themselves as more likely to lose something, and the most common answer for what might be lost in the health/safety risks was "my life." A further question is whether different age groups process risk information differently. For instance, fuzzy-trace theory suggests that there are two types of processing-gist based (less precise, more qualitative) and verbatim (more precise, more quantitative), which can influence how people make decisions that involve risk (Reyna, 2004). Reyna and colleagues found that these processes can vary by age such that adolescents used more verbatim-based processing, while adults used more gist-based processing (Reyna et al., 2011). If this trend continues as we age, the older adults may use even more gist-based processing. The current research did not measure nor manipulate the type of processing, but future research could examine the role of type of processing in age differences in risk.

Another question is which of the motivations are most important for each age group? The risk-return models suggest that people evaluate the costs and benefits of engaging in the risky behavior and make a decision based on the overall analysis. Contrary to our expectations, we found that young adults rated health/safety risks as more unpleasant than the older adults, yet they also rated themselves as more likely to engage in the behaviors. This suggests that the young adults feel that possible gains are worth some unpleasantness or that the unpleasantness is far enough into the future that they do not take it into consideration, whereas older adults may be more likely to think about future consequences. Future research could investigate whether gains or losses are more important and possibly better predictors of risky behavior for each age group.

Our research omitted some important domains, such as financial risk. With our diverse population, we were unable to find financial items that were equally relevant for both young and older adults. The young adults in our sample were college students who mostly did not have a steady income or pay for their own expenses, while the older adults were mostly retired and had different types of incomes that may not accurately predict their level of wealth. Therefore, we had trouble finding hypothetical financial risky behaviors that would overlap for the two different populations. Further, research on age differences in financial risk shows inconsistent results. Some studies found that older adults perform worse on gambling tasks (Fein, McGillivray, \& Finn, 2007; Denburg, Tranel, \& Bechara, 2005). However, one study using the Iowa Gambling Task found that a subset of older adults showed better decision-making skills than younger adults (Denburg, Recknor, Bechara, \& Tranel, 2006). Some research has found that there is a curvilinear relationship between financial risk tolerance and age, such that people tend to become more risk seeking until they reach retirement, at which point they become less risk seeking (e.g., Riley \& Chow, 1992). These results indicate that age and financial risk may have a more complicated relationship as we did not observe reversals in the trends for any of the five risk domains that we tested (refer to footnote 2).

Future research should examine differences within domains in addition to differences between domains. Although we included multiple risky behaviors for each domain, there are many other risky behaviors in each domain that might be examined. As there is variability among domains, there may also be variability within each domain. For instance, our results might have been because of the particular items 
that we included in our scale as we had a limited number of items for each domain. Additionally, specific risks such as some health/safety risks may be more appealing to young adults, while others are more appealing to older adults.

Additionally, the items from our environmental risk domain were often labeled as health/safety risks by our participants in Study 1 yet did not show any age differences indicating that there may be subcategories within each domain based on factors such as control over the outcome. Most of the items in the environmental risk domain involved being exposed to something harmful, such as radiation or pesticides, which very few people would choose to do deliberately but are also somewhat hard to deliberately avoid. Therefore, the lack of control might eliminate any age differences for these types of health/safety risks. Future research should examine the relationship between control over the situation and age differences as well as other subcategories that might exist within each domain.
In addition, we defined our risk domains based on the domain of the possible loss. However, as we saw in the young adults with the health/safety risks, the gains were not always in the same domain as the loss. A health risk was sometimes seen as worth taking in exchange for a social gain. Future research could investigate the relative importance of losses and gains in domains other than the primary domain defined by the loss.

While our studies illustrate significant age differences in risk preferences across domains, further research is needed to fully understand why these differences occur. Using our qualitative data, we have begun to speculate on how and why risk preferences change throughout the life span. However, future research should delve further into the types of gains and losses for each risk domain and how these tradeoffs relate to the participants' enjoyment of the risky behavior.

\section{APPENDIX}

\begin{tabular}{|c|c|c|}
\hline Item number & Risk wording & Domain \\
\hline $1^{\mathrm{ab}}$ & Admitting that your tastes are different from those of a friend & Social \\
\hline $2^{\mathrm{b}}$ & Engaging in unprotected sex & Health/Safety \\
\hline $3^{\mathrm{ab}}$ & Having an affair with someone who is currently in a committed relationship & Ethical \\
\hline 4 & Being exposed to second-hand smoke & Environmental \\
\hline 5 & Owning a handgun & Other \\
\hline $6^{\mathrm{a}}$ & Riding in a car with a driver who has been drinking & Health/Safety \\
\hline $7^{\mathrm{ab}}$ & Disagreeing with an authority figure (e.g. professor or boss) on a major issue & Social \\
\hline $8^{\mathrm{ab}}$ & Driving a car without wearing a seat belt & Health/Safety \\
\hline $9^{\mathrm{ab}}$ & Passing off somebody else's work as your own & Ethical \\
\hline 10 & Being exposed to nuclear waste & Environmental \\
\hline 11 & Being a victim of violent crime & Other \\
\hline $12^{\mathrm{b}}$ & Expressing an unpopular opinion in a meeting at work or school & Social \\
\hline $13^{\mathrm{b}}$ & Riding a bike or motorcycle without a helmet & Health/Safety \\
\hline $14^{\mathrm{b}}$ & Cheating on an exam & Ethical \\
\hline 15 & Being exposed to pesticides & Environmental \\
\hline 16 & Leaving your car or bike unlocked & Other \\
\hline $17^{\mathrm{c}}$ & Moving to a city far away from your family & Social \\
\hline $18^{\mathrm{b}}$ & Sunbathing without sunscreen & Health/Safety \\
\hline $19^{\mathrm{a}}$ & Downloading or copying music or videos illegally & Ethical \\
\hline 20 & Being exposed to carbon monoxide in your home & Environmental \\
\hline 21 & Leaving your house or apartment unlocked & Other \\
\hline $22^{\mathrm{ab}}$ & Arguing with a friend about an issue on which he or she has a very different opinion & Social \\
\hline $23^{\mathrm{b}}$ & Walking home alone at night in an unsafe area of town & Health/Safety \\
\hline $24^{\mathrm{a}}$ & Regularly eating unhealthy foods & Health/Safety \\
\hline $25^{\mathrm{ab}}$ & Shoplifting & Ethical \\
\hline $26^{\mathrm{a}}$ & Drinking out of the same glass as someone else & Health/Safety \\
\hline 27 & Being exposed to harmful bacteria in food & Environmental \\
\hline 28 & Taking a shortcut that may have more traffic instead of going your usual route & Other \\
\hline $29^{\mathrm{a}}$ & Consuming five or more alcoholic drinks in a single evening & Health/Safety \\
\hline $30^{\mathrm{ab}}$ & Taking a job that you enjoy over one that is more prestigious but less enjoyable & Social \\
\hline 31 & Using any sort of recreational drug (e.g., marijuana, cocaine, or oxycontin). & Health/Safety \\
\hline $32^{\mathrm{ab}}$ & Stealing an additional TV cable connection off the one you pay for & Ethical \\
\hline 33 & Regularly not washing your hands before eating & Health/Safety \\
\hline 34 & Getting caught in a natural disaster (i.e., flood, tornado, or hurricane) & Environmental \\
\hline 35 & Getting to the airport less than an hour before your flight leaves & Other \\
\hline 36 & Having multiple sexual partners in a short amount of time & Health/Safety \\
\hline $37^{\mathrm{a}}$ & Going to a social event by yourself & Social \\
\hline 38 & Being exposed to harmful amounts of radiation & Environmental \\
\hline 39 & Regularly driving more than $10 \mathrm{mi}$ an hour over the speed limit & Other \\
\hline 40 & Catching a sexually transmitted disease & Health/Safety \\
\hline
\end{tabular}

${ }^{\mathrm{a}}$ Used in Study 2

${ }^{\mathrm{b}}$ Taken from the DOSPERT

${ }^{\mathrm{c}}$ Omitted in Study 1 


\section{REFERENCES}

Albert, D., \& Steinberg, L. (2011). Judgment and decision making in adolescence. Journal of Research on Adolescence, 21(1), 211-224.

Arnett, J. (1992). Reckless behavior in adolescence: A developmental perspective. Developmental Review, 12(4), 339-373.

Blais, A., \& Weber, E. U. (2006). A domain-specific risk-taking (DOSPERT) scale for adult populations. Judgment and Decision Making, 1(1), 33-47.

Botwinick, J., \& Thompson, L. W. (1966). Components of reaction time in relation to age and sex. The Journal of Genetic Psychology: Research and Theory on Human Development, 108(2), $175-183$.

Carstensen, L. L. (1993). Motivation for social contact across the life span: A theory of socioemotional selectivity, In J. E. Jacobs (Ed.), Nebraska Symposium on Motivation, 1992: Developmental perspectives on motivation (pp. 209-254). Lincoln, NE, US: University of Mebraska Press.

Centers for Disease Control and Prevention (CDC). (2008). HIV/ AIDS among Persons Aged 50 and Older. Atlanta, GA: U.S. Department of Health and Human Services.

Chaubey, N. P. (1974). Effect of age on expectancy of success and on risk-taking behavior. Journal of Personality and Social Psychology, 29(6), 774-778.

Chou, K., Lee, T. M. C., \& Ho, A. H. Y. (2007). Does mood state change risk taking tendency in older adults? Psychology and Aging, 22(2), 310-318.

Denburg, N. L., Recknor, E. C., Bechara, A., \& Tranel, D. (2006). Psychophysiological anticipation of positive outcomes promotes advantageous decision-making in normal older persons. International Journal of Psychophysiology, 61(1), 19-25.

Denburg, N. L., Tranel, D., \& Bechara, A. (2005). The ability to decide advantageously declines prematurely in some normal older persons. Neuropsychologia, 43(7), 1099-1106.

Diamond, J. (2013, January 28). That daily shower can be a killer. New York Times.

Dror, I. E., Katona, M., \& Mungur, K. (1998). Age differences in decision making: To take a risk or not? Gerontology, $44(2)$ 67-71.

Fein, G., McGillivray, S., \& Finn, P. (2007). Older adults make less advantageous decisions than younger adults: Cognitive and psychological correlates. Journal of the International Neuropsychological Society, 13(3), 480-489.

Figner, B., \& Weber, E. U. (2011). Who takes risks when and why? Determinants of risk taking. Current Directions in Psychological Science, 20(4), 211-216.

Fredrickson, B. L., \& Carstensen, L. L. (1990). Choosing social partners: How old age and anticipated endings make people more selective. Psychology And Aging, 5(3), 335-347.

Gardner, M., \& Steinberg, L. (2005). Peer influence on risk taking, risk preference, and risky decision making in adolescence and adulthood: An experimental study. Developmental Psychology, 41(4), 625-635.

Heckhausen, J., Dixon, R. A., \& Baltes, P. B. (1989). Gains and losses in development throughout adulthood as perceived by different adult age groups. Developmental Psychology, 25(1), $109-121$.

Hoyle, R. H., Stephenson, M. T., Palmgreen, P., Pugzles Lorch, E., \& Donohew, R. L. (2002). Reliability and validity of a brief measure of sensation seeking. Personality and Individual Differences, 32(3), 401-414.

Kahneman, D., \& Tversky, A. (1979). On the interpretation of intuitive probability: A reply to Jonathan Cohen. Cognition, 7(4), 409-411.

Kogan, N., \& Wallach, M. A. (1961). Age changes in values and attitudes. Journal of Gerontology, 16, 272-280.

Kovalchik, S., Camerer, C. F., Grether, D. M., Plott, C. R., \& Allman, J. M. (2005). Aging and decision making: A comparison between neurologically healthy elderly and young individuals. Journal of Economic Behavior \& Organization, 58 (1), 79-94

Leichter, H. M. (1997). Morality and health, In A. M. Brandt, \& P. Rozin (Eds.), Morality and health (pp. 359-378). New York, NY: Routledge Inc.

MacPherson, S. E., Phillips, L. H., \& Della Sala, S. (2002). Age, executive function and social decision making: A dorsolateral prefrontal theory of cognitive aging. Psychology and Aging, 17(4), 598-609.

Mather, M. (2006). A review of decision-making processes: Weighing the risks and benefits of aging. When I'm 64, 145; $145-173 ; 173$

Mather, M., Mazar, N., Gorlick, M. A., Lighthall, N. R., Burgeno, J., Schoeke, A., \& Ariely, D. (2012). Risk preferences and aging: The "certainty effect" in older adults' decision making. Psychology and Aging, 27(4), 801-816.

Okun, M. A. (1976). Adult age and cautiousness in decision: A review of the literature. Human Development, 19(4), 220-233.

Patton, J. H., Stanford, M. S., \& Barratt, E. S. (1995). Factor structure of the Barratt Impulsiveness Scale. Journal of Clinical Psychology, 51(6), 768-774.

Reece, M., Herbenick, D., Schick, V., Sanders, S. A., Dodge, B., \& Fortenberry, J. D. (2010). Condom use rates in a national probability sample of males and females ages 14 to 94 in the United States. Journal of Sexual Medicine, 7, 266-276.

Reyna, V. F. (2004). How people make decisions that involve risk: A dual-processes approach. Current Directions in Psychological Science, 13(2), 60-66.

Reyna, V. F., Estrada, S. M., DeMarinis, J. A., Myers, R. M., Stanisz, J. M., \& Mills, B. A. (2011). Neurobiological and memory models of risky decision making in adolescents versus young adults. Journal Of Experimental Psychology: Learning, Memory, And Cognition, 37(5), 1125-1142.

Riley, W. B., \& Chow, K. V. (1992). Asset allocation and individual risk aversion. Financial Analysts Journal, 48, 32-38.

Roalf, D. R., Mitchell, S. H., Harbaugh, W. T., \& Janowsky, J. S. (2012). Risk, reward, and economic decision making in aging. The Journals of Gerontology Series B: Psychological Sciences and Social Sciences, 67B(3), 289-298.

Rolison, J. J., Hanoch, Y., \& Wood, S. (2012). Risky decision making in younger and older adults: The role of learning. Psychology and Aging, 27(1), 129-140.

Roth, M., \& Hammelstein, P. (2012). The need inventory of sensation seeking (NISS). European Journal of Psychological Assessment, 28(1), 11-18.

Samanez-Larkin, G., Kuhnen, C. M., Yoo, D. J., \& Knutson, B. (2010). Variability in nucleus accumbens activity mediates age-related suboptimal financial risk taking. The Journal of Neuroscience, 30(4), 1426-1434.

Schoemaker, P. J. H. (1990). Are risk preferences related across payoff domains and response modes? Management Science, 36, 1451-1463.

Spinella, M. (2007). Normative data and a short form of the Barratt Impulsiveness Scale. International Journal of Neuroscience, 117(3), 359-368.

Wallach, M. A., \& Kogan, N. (1961). Aspects of judgment and decision making: Interrelationships and changes with age. Behavioral Science, 6, 23-36.

Weber, E. U. (1998). Who's afraid of a little risk? New evidence for general risk aversion. In J. Shanteau, B. A. Mellers, \& D. Schum (Eds.), Decision research from Bayesian approaches to normative systems: Reflections on the Countributions of Ward Edwards (pp. 53-64). Norwell, MA: Kluwer.

Weber, E. U., Blais, A., \& Betz, N. E. (2002). A domain-specific risk-attitude scale: Measuring risk perceptions and risk behaviors. Journal of Behavioral Decision Making, 15(4), 263-290.

Weller, J. A., Levin, I. P., \& Denburg, N. L. (2011). Trajectory of risky decision making for potential gains and losses from ages 5 to 85. Journal of Behavioral Decision Making, 24(4), 331-344.

Welte, J., Barnes, G., Wieczorek, W., Tidwell, M., \& Parker, J. (2001). Alcohol and gambling pathology among U. S. adults: 
Prevalence, demographic patterns and comorbidity. Journal of Studies on Alcohol, 62(5), 706-712.

Zamarian, L., Sinz, H., Bonatti, E., Gamboz, N., \& Delazer, M. (2008). Normal aging affects decisions under ambiguity, but not decisions under risk. Neuropsychology, 22(5), 645-657.

\section{Authors' biographies:}

Emily M. Bonem received her $\mathrm{PhD}$ from the University of Michigan and is currently at Purdue University. Her research interests are decision making, emotions, and motivation.

Phoebe C. Ellsworth is the Frank Murphy Distinguished University Professor of Psychology and Law at the University of Michigan. She received her BA from Harvard and her $\mathrm{PhD}$ from Stanford. She is a fellow of the APA, APS, SPSP, ISRE, and the American Academy of Arts and Sciences. She studies emotion and also Psychology and Law.

Richard Gonzalez received his PhD from Stanford University and is currently at the University of Michigan. He specializes in decision making, social psychology, and mathematical modeling. He directs the Biosocial Methods Collaborative at the Institute for Social Research.

Authors' addresses:

Emily M. Bonem, Phoebe C. Ellsworth and Richard Gonzalez, Department of Psychology, University of Michigan, Ann Arbor, MI USA 